\title{
Serum transforming growth factor-beta 1 levels in normoalbuminuric and normotensive patients with type 2 diabetes. Effect of metformin and rosiglitazone
}

\author{
Serkan Yener, ${ }^{1}$ Abdurrahman Comlekci, ${ }^{1}$ Baris Akinci, ${ }^{1}$ Pinar Akan, ${ }^{2}$ \\ Tevfik Demir, ${ }^{1}$ Firat Bayraktar, ${ }^{1}$ Sena Yesil ${ }^{1}$ \\ ${ }^{1}$ Dokuz Eylul University, Department of Internal Medicine, Division of Endocrinology and Metabolism, ${ }^{2}$ Dokuz Eylul \\ University, Department of Biochemistry, Izmir, Turkey
}

\begin{abstract}
OBJECTIVE: a)To determine serum Transforming Growth Factor-beta 1 (TGF-ß1) levels in patients with type 2 diabetes who do not have diabetes related complications and in healthy controls, b) to evaluate the effects of metformin and rosiglitazone on TGF-p1 levels. DESIGN: In the washout period, 61 patients with Fasting Plasma Glucose levels (FPG) higher than 140 $\mathrm{mg} / \mathrm{dl}$, Postprandial Glucose (PPG) levels higher than $180 \mathrm{mg} / \mathrm{dl}$ and A1c levels exceeding 6.5\% were treated with glimperide. After 4 weeks, 39 of these patients were randomised to receive either metformin or rosiglitazone for 12 weeks. Thirty healthy controls were also studied. RESULTS: There were no significant differences with regard to age, gender, body weight and BMI between patients and healthy controls. Type 2 diabetics had higher waist circumference, FPG, total cholesterol, LDL-cholesterol and triglyceride levels. Baseline TGF- $\beta 1$ levels in diabetics were higher than in controls $(29.84 \pm 7.04 \mathrm{ng} / \mathrm{ml}$ vs $11.37 \pm 4.06 \mathrm{ng} / \mathrm{ml}, \mathbf{p}<0.001)$. Metformin or rosiglitazone did not significantly modify the TGF- $\beta 1$ levels. In a multiple regression analysis FPG was the only variable that was significantly associated with plasma TGF- $\beta 1$ levels. CONCLUSION: The elevated levels of TGF- $\beta 1$ in subjects with type 2 diabetes possibly indicate a tendency for renal and endothelial damage in such patients. The association of TGF- 11 with FPG possibly links poor diabetic control to vascular damage, leading to diabetic complications. Lack of changes in the levels of TGF- $\beta 1$ after therapy may reflect inadequate therapy duration.
\end{abstract}

Key words: Metformin, Rosiglitazone, TGF- $\beta 1$, Type 2 diabetes mellitus

\section{INTRODUCTION}

There is growing evidence that renal and endothelial involvement in type 2 diabetes can occur without any diabetes related clinical complications. Thus, it has been noticed that altered structural changes, such as increased glomerular basal membrane width 
and mesengium fractional volume, can exist in normoalbuminuric type 2 diabetic patients. ${ }^{1}$ It has also been proven that endothelial dysfunction is present even in uncomplicated type 2 diabetes. $^{2}$

Transforming Growth Factor beta (TGF- $\beta$ ) is an important cytokine for the development of renal injury in type 2 diabetic patients. The TGF- $\beta$ family includes multifunctional molecules that exert specific effects on cell proliferation, differentiation, migration, development, tissue remodelling and repair. ${ }^{3}$ TGF- $\beta 1$, unlike TGF- $\beta 2$ and TGF- $\beta 3$, is known to be at increased concentrations in healthy blood vessel walls ${ }^{4}$ and is one of the three isoforms of TGF- $\beta$ with the most prominent fibrotic properties.

Insulin resistance and consequent hyperinsulinemia were demonstrated as increasing TGF- $\beta 1$ expression in cell culture as well as in humans. ${ }^{5}$ Anderson et al have shown that insulin significantly increases TGF- $\beta 1$ expression from mesengial cells in vitro. ${ }^{6}$ Insulin was also found to stimulate TGF- $\beta 1$ expression in epithelial cells of the proximal tubule which, in turn, led to an increase in type IV collogen gene expression and accumulation in the extracellular matrix. ${ }^{7}$ Furthermore, in vitro studies showed that in high glucose concentrations, TGF- $\beta$ triggers hypertrophy and extracelluler matrix deposition in renal proximal tubuler cells, mesengial cells, epithelial cells, endothelial cells and fibroblasts. ${ }^{8}$ TGF- $\beta$ signaling plays important roles in the development of atherosclerosis. ${ }^{9}$ TGF- $\beta$ and receptors are widely expressed by smooth muscle cells, macrophages and $\mathrm{T}$ cells in human atherosclerotic lesions during development of fatty streaks and subsequant atheroma. ${ }^{10}$

Metformin and rosiglitazone are widely used in type 2 diabetes management. In the UK Prospective Diabetes Study (UKPDS), it was demonstrated that metformin was associated with a decrease in cardiovascular mortalitiy and morbidity independent of glycemic control in overweight type 2 diabetic patients. ${ }^{11}$ This effect was attributed to the vasculoprotective effects of metformin. Other studies also demonstrated that metformin had benefical effects on Plasminogen Activator Inhibitor-1 (PAI-1), von Willebrand Factor (vWF) and fibrinogen. ${ }^{12-14}$ Metformin was also shown to improve endothelial dysfuntion. ${ }^{15,16}$ Rosiglitazone therapy was shown to reduce serum C reactive protein levels in type 2 diabetic patients. ${ }^{17}$ Furthermore, rosiglitazone therapy was shown to ameliorate endothelial dysfunction independent of glucose control. ${ }^{18}$ Rosiglitazone has additional renoprotective effects either through reduction of albumin excretion or by preventing the occurrence of microalbuminuria. ${ }^{19}$

There are not enough data in the literature demonstrating TGF- $\beta 1$ levels in type 2 diabetic patients without diabetes related complications. Likewise, effects of metformin or rosiglitazone on TGF- $\beta 1$ have not as yet been evaluated. In this study, our aim was to evaluate TGF- $\beta 1$ levels in normotensive, normoalbuminuric, poorly controlled type 2 diabetic patients without any complications. In addition, we also evaluated the effects of 12 weeks metformin and rosiglitazone on TGF- $\beta 1$ levels.

\section{MATERIALS AND METHODS}

Patients with type 2 diabetes ( in accordance with the American Diabetes Association criteria defined in 2005), diagnosed at least 6 months earlier, aged 30-70 years, with Fasting Plasma Glucose (FPG) over 140 $\mathrm{mg} / \mathrm{dl}$, 2-hours Postprandial Glucose (PPG) over 180 $\mathrm{mg} / \mathrm{dl}$ and $\mathrm{A}_{\mathrm{cc}}$ over $6.5 \%$ were included in the study for the washout period. Exclusion criteria were as follows: hypertension ( 2 consecutive measurements higher than $130 / 80 \mathrm{~mm}-\mathrm{Hg}$ ), diabetic retinopathy, diabetic polyneuropathy, history of a cardiovascular and/or cerebrovascular event, history of any chronic disease, pregnancy, childbearing potential, Body Mass Index (BMI) over $40 \mathrm{~kg} / \mathrm{m}^{2}$, abnormal resting electrocardiography or positive treadmill exercise test, angina pectoris, intermittent claudication, microalbuminuria ( $\geq 30 \mathrm{mg} /$ day), transaminase levels exceeding 2.5 times normal and serum creatinine levels over 1.4 $\mathrm{mg} / \mathrm{dl}$. Patients who were being treated with insulin (or with a history of insulin treatment), Angiotensin Converting Enzyme (ACE) inhibitors, angiotensin receptor antagonists, anticoagulant drugs or antiobesity drugs were also excluded. Sixty-one type 2 diabetic patients and 30 age, gender and BMI matched healthy controls without any diseases were included in the study. Written informed consent was obtained from each participant.

The study was designed to be in two phases. The 
first phase was the washout period and lasted 4 weeks. During the washout period, oral antidiabetics were switched to glimepride at the appropriate dose (minimum $1 \mathrm{mg}$ and maximum $4 \mathrm{mg}$ ) adjusted according to the patient's plasma glucose levels. After 4 weeks of washout period, 39 patients were included in the second phase of the study and received either metformin or rosiglitazone. Twenty-two patients were not randomised because of microalbuminuria, hypertension, withdrawal of informed consent or for the need of insulin therapy. The patients with FPG over 180 $\mathrm{mg} / \mathrm{dl}$ continued glimepride besides metformin or rosiglitazone. Metformin was administered at the dose of $1700 \mathrm{mg} /$ day in two divided doses (after breakfast and dinner) and the daily rosiglitazone dose was 4 $\mathrm{mg}$ and was given before breakfast. The patients with Low Density Lipoprotein Choleserol (LDL-C) higher than $130 \mathrm{mg} / \mathrm{dl}$ were treated with simvastatin $(10 \mathrm{mg} /$ day or $20 \mathrm{mg} /$ day). No other anti-lipidemic drugs were used during the study. The patients were followed for 12 weeks. During the follow-up period, drug doses were not changed and no other drugs were added to the therapeutic regimen.

At the begining and at the end of the randomisation phase the patients were evaluated. Following 8-10 hours of overnight fasting a complete medical history was taken and detailed physical examination was performed. Height $(\mathrm{m})$, weight $(\mathrm{kg})$ and waist circumference $(\mathrm{cm})$ were measured with the subjects in light clothing and without shoes. Two consecutive blood pressure measurements were recorded, using a sphygmomanometer, in the sitting position after 5 minutes resting. Blood samples for laboratory investigations were obtained from the antecubital vein with a vacutainer between 08:00 and 09:00 hr. A PPG sample was obtained 2 hours after breakfast.

Laboratory investigations were as follows: FPG, 2-hours PPG, $\mathrm{A}_{1}$ c, total cholesterol, High Density Lipoprotein Cholesterol (HDL-C), triglycerides, calculated LDL-C and serum TGF- $\beta 1$. A twenty-four hour urine sample was collected for the detection of microalbuminuria. Serum samples for fasting and PPG and lipid parameters were obtained by centrifugation at $2000 \mathrm{bpm}$ for 15 minutes at room temperature. $A_{1 c}$ measurements were performed with fresh samples. Serum samples for TGF- $\beta 1$ were obtained by centrifugation at $2000 \mathrm{bpm}$ for 15 minutes at $4^{\circ} \mathrm{C}$. All samples were stored at $-80^{\circ} \mathrm{C}$.

TGF- $\beta 1$ levels were measured using available ELISA kits (Biosource, Nivelles, Belgium). FPG, triglyceride, total cholesterol, LDL-C and HDLC were measured by Roche/Hitachi D/P Modular System Autoanalyzer (Roche Diagnostics, Basel, Switzerland).

Statistical analysis was performed with SPSS, version 11.0 for Windows. Comparisons between groups were determined with Independent Samples t-test or Mann Whitney U-test. Comparison of related samples was assessed with the Wilcoxon test. Correlations were assessed by Spearman correlation. Multiple regression analysis was used to check the effects of all independent factors that potentially affect TGF- $\beta 1$. P value $<0.05$ ( 2 tailed) was considered to be significant.

\section{RESULTS}

Sixty-one patients were included in the washout phase. After a 4-week washout period, 22 patients were excluded and 39 patients ( 18 females, 21 males) were followed during the randomisation period. The anthropometric and laboratory parameters of type 2 diabetic subjects and healthy controls at the

Table 1. Anthropometric and laboratory parameters of patients and healthy controls at the beginning of the study (data are presented as mean value $\pm \mathrm{SD}$ ). Data are in Conventional Units (CU). [Correction Factor $(\mathrm{CF}) \times \mathrm{CU}=\mathrm{SI}$ unit, $\mathrm{CF}$ for glucose level is 0.055 and $\mathrm{CF}$ for lipid values is 0.02586 ].

\begin{tabular}{lccc}
\hline & $\begin{array}{c}\text { Type 2 } \\
\text { diabetics } \\
(\mathbf{n = 3 9})\end{array}$ & $\begin{array}{c}\text { Healthy } \\
\text { controls } \\
(\mathbf{n = 3 0})\end{array}$ & $\mathbf{p}$ \\
\hline Sex $(\mathrm{F} / \mathrm{M})$ & $18 / 21$ & $16 / 14$ & 0.631 \\
Age (years) & $53.1 \pm 7.7$ & $49.5 \pm 9.4$ & 0.089 \\
Body weight $(\mathrm{kg})$ & $73.9 \pm 11.3$ & $72.0 \pm 10.9$ & 0.486 \\
BMI $\left(\mathrm{kg} / \mathrm{m}^{2}\right)$ & $27.3 \pm 2.8$ & $26.6 \pm 3.1$ & 0.191 \\
Waist circumference $(\mathrm{cm})$ & $90.7 \pm 8.5$ & $85.2 \pm 11.5$ & 0.031 \\
FPG $(\mathrm{mg} / \mathrm{dl})$ & $177.0 \pm 52.4$ & $91.3 \pm 5.9$ & $<0.001$ \\
A1c $(\%)$ & $8.2 \pm 1.6$ & - & - \\
Total cholesterol (mg/dl) & $200.3 \pm 43.7$ & $173.2 \pm 23.4$ & 0.006 \\
LDL-C (mg/dl) & $117.5 \pm 34.9$ & $101.7 \pm 19.3$ & 0.043 \\
HDL-C (mg/dl) & $50.9 \pm 13.1$ & $49.8 \pm 12.7$ & 0.750 \\
Triglyceride (mg/dl) & $161.7 \pm 93.0$ & $113.9 \pm 51.6$ & 0.022 \\
Serum TGF- $\beta 1(\mathrm{ng} / \mathrm{ml})$ & $29.84 \pm 7.04$ & $11.37 \pm 4.06$ & $<0.001$ \\
\hline
\end{tabular}


beginning of the randomisation period are shown in Table 1. Type 2 diabetic subjects were found to have higher waist circumference $(\mathrm{p}=0.031)$ and higher levels of FPG $(p<0.001)$, total cholesterol $(p=0.006)$, LDL-C $(p=0.043)$, triglyceride $(p=0.022)$ and TGF$\beta 1(p<0.001)$ compared to healthy controls.

A group of 16 patients (6 women, 10 men) was treated with metformin and the remaining 23 patients ( 12 women, 11 men) were given rosiglitazone. The mean ages of the metformin and rosiglitazone groups were 54.4 \pm 7.2 and $52.3 \pm 8.1$, respectively. Age $(p=0.396)$, gender $(p=0.516)$, BMI $(p=0.641)$, waist circumference $(p=0.712)$, FPG $(p=0.294)$, PPG $(p=0.954), A_{1 c}(p=0.448)$, total cholesterol $(\mathrm{p}=0.682)$, triglyceride $(\mathrm{p}=0.989)$, HDL-C $(\mathrm{p}=0.275)$, LDL-C $(p=0.855)$ and TGF- $\beta 1(p=0.224)$ levels were comparable in the two groups at the beginning of the randomisation phase. The basal and the 12th week anthropometric and laboratory parameters of the patients are shown in Table 2.

After 12 weeks' treatment with metformin, $\mathrm{A}_{1 \mathrm{c}}$ levels were significantly lower $(\mathrm{p}=0.027)$ compared with the basal values and the same trend was observed in weight and BMI ( $\mathrm{p}$ value for body weight and BMI is 0.054$)$. There was no significant change in waist circumference $(p=0.710)$, total cholesterol $(p=0.205)$, triglyceride $(p=0.215)$, HDL-C $(p=0.603)$, LDL-C $(p=0.326)$ and serum TGF- $\beta 1(p=0.301)$ levels with metformin therapy.

In the rosiglitazone group, FPG and $\mathrm{A}_{1 \mathrm{c}}$ values decreased significantly after 12 weeks $(p=0.004$ and $\mathrm{p}=0.003$, respectively) (Table 2 ). There was no significant change in BMI $(p=0.552)$, waist circumference $(p=0.117)$ and PPG $(p=0.313)$ when compared with baseline values. Total cholesterol $(p=0.080)$, LDL-C $(p=0.163)$ and HDL-C $(p=0.983)$ did not differ significantly after 12 weeks' treatment, but triglyceride levels increased ( $p=0.025)$ after 12 weeks' rosiglitazone treatment. Serum TGF- $\beta 1$ levels did not change significantly in the rosiglitazone group $(\mathrm{p}=0.362)$.

The serum TGF- $\beta 1$ levels were correlated with age $(r=0.243 \mathrm{p}=0.044)$, FPG $(\mathrm{r}=0.523 \mathrm{p}<0.001)$, total cholesterol $(\mathrm{r}=0.299 \mathrm{p}=0.016)$ and LDL-C $(\mathrm{r}=0.261 \mathrm{p}=0.037)$ (Table 3$)$. In a multiple regression analysis after adjustment for age, FPG, body weight, BMI, waist circumference, total cholesterol, triglyceride, HDL-C and LDL-C, FPG remained the only variable that was associated significantly and independently with plasma TGB- $\beta 1$ levels (Table 4 and Figure 1). TGF- $\beta 1$ levels did not differ between men and women $(21.77 \pm 12.01$ vs $21.85 \pm 9.90$, respectively, $\mathrm{p}=0.975)$.

In the type 2 diabetes group, basal TGF- $\beta 1$ was

Table 2. The baseline and the third month anthropometric and laboratory parameters of the patients. Data are presented as mean value \pm SD. Data are in Conventional Units $(\mathrm{CU})$. [Correction Factor $(\mathrm{CF}) \times \mathrm{CU}=\mathrm{SI}$ unit, CF for glucose level is 0.055 and $\mathrm{CF}$ for lipid values is 0.02586$]$.

\begin{tabular}{|c|c|c|c|c|}
\hline & $\begin{array}{l}\text { Metformin (baseline) } \\
n=16\end{array}$ & $\begin{array}{c}\text { Metformin } \\
\text { (12 weeks) } \\
n=16\end{array}$ & $\begin{array}{l}\text { Rosiglitazone (baseline) } \\
n=23\end{array}$ & $\begin{array}{c}\text { Rosiglitazone } \\
\text { (12 weeks) } \\
\text { n=23 }\end{array}$ \\
\hline Body weight (kg) & $73.4 \pm 11.4$ & $72.0 \pm 10.7^{*}$ & $74.3 \pm 11.4$ & $73.6 \pm 11.7$ \\
\hline $\operatorname{BMI}\left(\mathrm{kg} / \mathrm{m}^{2}\right)$ & $27.0 \pm 2.4$ & $26.3 \pm 2.3$ & $27.4 \pm 3.0$ & $27.2 \pm 3.3$ \\
\hline Waist circumference $(\mathrm{cm})$ & $91.3 \pm 9.1$ & $91.1 \pm 9.1$ & $90.3 \pm 8.2$ & $91.8 \pm 7.6$ \\
\hline $\mathrm{FPG}(\mathrm{mg} / \mathrm{dl})$ & $166.3 \pm 53.0$ & $146.25 \pm 45.9$ & $184.5 \pm 51.8$ & $146.7 \pm 22.7 \&$ \\
\hline 2-h PPG (mg/dl) & $255.4 \pm 88.1$ & $212.4 \pm 61.6$ & $245.7 \pm 102.6$ & $211.2 \pm 62.7$ \\
\hline $\mathrm{A} 1 \mathrm{c}(\%)$ & $8.0 \pm 1.2$ & $7.0 \pm 1.0 \#$ & $8.4 \pm 1.8$ & $7.3 \pm 1.1 \&$ \\
\hline Total cholesterol $(\mathrm{mg} / \mathrm{dl})$ & $199.2 \pm 47.7$ & $217.3 \pm 32.5$ & $201.0 \pm 41.7$ & $217.9 \pm 53.9$ \\
\hline LDL-C (mg/dl) & $120.3 \pm 36.0$ & $130.4 \pm 22.6$ & $115.5 \pm 34.8$ & $129.6 \pm 40.70$ \\
\hline HDL-C (mg/dl) & $47.2 \pm 10.6$ & $48.1 \pm 12.2$ & $53.3 \pm 14.2$ & $52.1 \pm 12.9$ \\
\hline Triglyceride (mg/dl) & $157.4 \pm 76.5$ & $194.0 \pm 110.3$ & $164.7 \pm 104.5$ & $208.7 \pm 184.4 \&$ \\
\hline Serum TGF- $\beta 1$ (ng/ml) & $28.24 \pm 6.01$ & $29.61 \pm 7.30$ & $30.95 \pm 7.60$ & $29.02 \pm 6.63$ \\
\hline
\end{tabular}

${ }^{*} \mathrm{p}=0.054$ vs Metformin (baseline), ${ }^{\#} 0.001<\mathrm{p}<0.05$ vs Metformin (baseline) and ${ }^{\&} 0.001<\mathrm{p}<0.05$ vs Rosiglitazone (baseline) 
Table 3. Correlation coefficients of baseline TGF- $\beta 1$ with other study parameters.

\begin{tabular}{lcc}
\hline Variables & $\mathbf{r}$ & $\mathbf{p}$ \\
\hline Age & 0.243 & 0.044 \\
FPG & 0.523 & $<0.001$ \\
Body weight & 0.056 & 0.650 \\
BMI & 0.171 & 0.159 \\
Waist circumference & 0.172 & 0.157 \\
Total cholesterol & 0.299 & 0.016 \\
Triglyceride & 0.170 & 0.179 \\
HDL-C & 0.068 & 0.593 \\
LDL-C & 0.261 & 0.037 \\
TGF- $\beta 1$ (12 weeks) & 0.504 & 0.001 \\
\hline
\end{tabular}

Table 4. Multiple regression analysis demonstrating the effects of the study parameters on TGF- $\beta 1$

\begin{tabular}{lcc}
\hline Variables & beta & $\mathbf{p}$ \\
\hline Age & 0.120 & 0.291 \\
FPG & 0.470 & $<0.001$ \\
Body weight & -0.056 & 0.772 \\
BMI & 0.130 & 0.398 \\
Waist circumference & 0.083 & 0.603 \\
Total cholesterol & 0.251 & 0.443 \\
Triglyceride & -0.232 & 0.161 \\
HDL-C & -0.078 & 0.619 \\
LDL-C & -0.005 & 0.985 \\
\hline
\end{tabular}

found to be strongly correlated with the 12 th week TGF- $\beta 1(r=0.504 p=0.001)$. Multiple regression analysis demonstrated that basal TGF- $\beta 1$ is an important factor affecting the 12 th week TGF- $\beta 1$ levels (beta $=0.594 \mathrm{p}=0.001$ ).

During the study, 4 patients from the metformin group and 6 patients from the rosiglitazone group were treated with simvastatin. Simvastatin therapy did not affect TGF- $\beta 1$ levels significantly (basal level of TGF- $\beta 131.51 \pm 8.00$ and 12th week level of TGF- $\beta 130.39 \pm 8.69 \mathrm{p}=0.856$ in simvastatin treated patients).

\section{DISCUSSION}

TGF- $\beta 1$ is a key cytokine for the development and progression of renal and endothelial involvement in

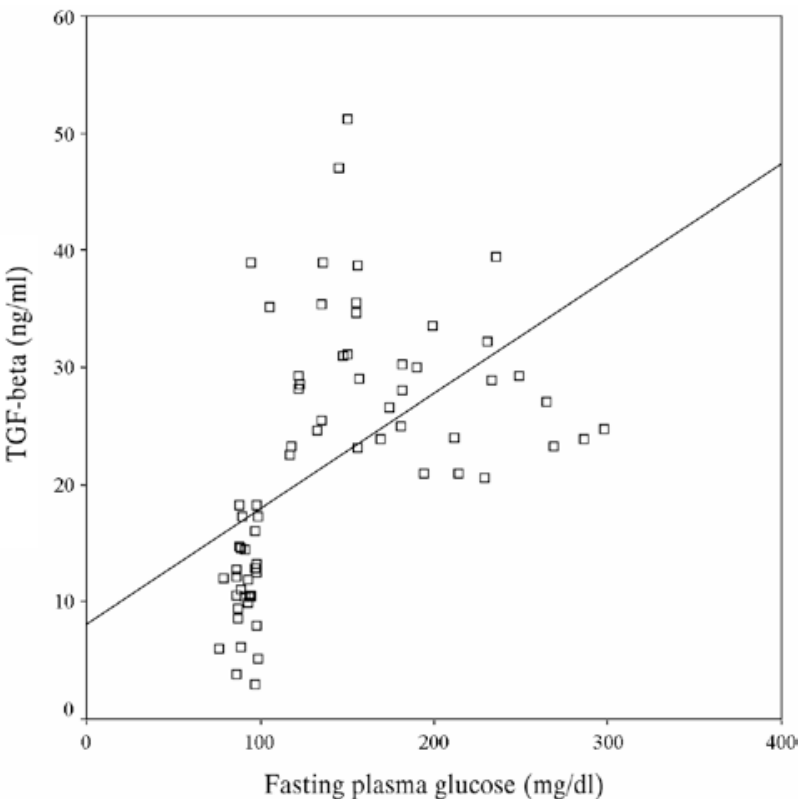

Figure 1. Correlation between FPG and TGF- $\beta 1$. Glucose is given in conventional units [Correction Factor $(\mathrm{CF}) \times \mathrm{CU}=\mathrm{SI}$ unit, CF for glucose level is 0.055].

type 2 diabetes. TGF- $\beta 1$ has fibrogenic properties and triggers hypertrophy and extracellular matrix deposition in renal and endothelial cells. ${ }^{8}$ TGF$\beta 1$ stimulates PAI-1 synthesis, ${ }^{20}$ induces monocyte chemotaxis and endothelial transmigration, promotes smooth muscle cell proliferation and migration ${ }^{21}$ and also stimulates proteoglycan production by smooth muscle cells, ${ }^{22}$ all of which constitute important steps for the development of atherosclerosis.

This study demonstrated that normotensive and normoalbuminuric patients with type 2 diabetes had higher levels of circulating TGF- $\beta 1$ than healthy controls. Metformin or rosiglitazone therapy for twelve weeks did not significantly affect serum TGF$\beta 1$ levels.

Previous studies have shown the important role of hyperglycemia and hyperinsulinemia in increasing TGF- $\beta 1$ expression through different pathways. ${ }^{23}$ Moreover, TGF- $\beta 1$ levels may increase in the prediabetic stage, an effect attributed to hyperinsulinism. In a previous study we demonstrated that TGF- $\beta 1$ levels are elevated in women with a history of gestational diabetes mellitus. ${ }^{24}$

As there is evidence demonstrating that adipose tissue might play a role in TGF- $\beta 1$ release,${ }^{20}$ the 
healthy controls were selected in such a way as to match the BMI of the patient group so that our results demonstrate the unique role of hyperglycemia for TGF- $\beta 1$ expression in the early stages of type 2 diabetes.

In the present study, 12 weeks' metformin or rosiglitazone therapy did not significantly change the TGF- $\beta 1$ levels in either group. This is the first study evaluating the effects of metformin or rosiglitazone on TGF- $\beta 1$ levels in humans. Despite a significant reduction of $A_{1 c}$ levels in the metformin and rosiglitazone groups and of FPG levels in the rosiglitazone group, TGF- $\beta 1$ levels remained constant. Furthermore, a slight reduction $(p=0.05)$ of body weight and BMI in the metformin group did not affect TGF- $\beta 1$ levels. The duration of therapy may be one of the possible factors explaining the lack of changes in TGF- $\beta 1$ values. It is known that the pleotropic effects of insulin sensitizers depends on the duration of therapy. Thus, extending the therapy duration may cause changes in TGF- $\beta 1$ levels. Besides, the drug dosage used in our study may not be adequate to cause changes in TGF- $\beta 1$ levels. Additionally, we may suggest that in type 2 diabetes, once the TGF- $\beta 1$ pathway is activated the conventional therapeutic interventions such as metformin or rosiglitazone could not significantly affect this particular pathway and specific treatment modalities such as ACE-inhibitors, AT-II antagonists or Anti-TGF- $\beta$ therapy may be needed.

Hyperglycemia causes an inflammatory reaction. ${ }^{25}$ In our study, the elevated levels of TGF- $\beta 1$ may reflect compensatory increases in subclinical inflammation, as TGF- $\beta$ pathways have immunsuppresive properties. It was previously demonstrated that TGF- $\beta$ is associated with an inhibition of the immune cell activation by blocking antigen presentation and/or production of interleukins, ${ }^{26,27}$ suppression of lymphocyte proliferation and differentiation and inhibition of tumour necrosis alfa and interleukin- $1 .^{28}$

In the present study, TGF- $\beta 1$ levels were found to correlate with age. Wang et al showed that aortic TGF- $\beta 1$ expression and TGF- $\beta 1$ activation increase with age and are dependent on the concomitant ageassociated increase in MMP-2 activity. It was shown that with aging TGF- $\beta 1$ contributes to increases in arterial stiffness. ${ }^{29-32}$ Therefore, elevation of circulat- ing TGF- $\beta 1$ levels with aging may contribute to the progression of atherosclerotic plaques. Furthermore, by demonstrating the correlation between TGF- $\beta 1$ and total and LDL-C, our results may offer an explanation for the role of the TGF- $\beta$ system in the development of atherosclerosis.

We found that basal and 12th week TGF- $\beta 1$ levels were strongly correlated. We may suggest that once the TGF- $\beta$ pathway is altered, it is difficult to inhibit its expression. Thus, the efficacy of additional treatment modalities may be evaluated for their possible effects on circulating TGF- $\beta 1$.

Our study has some limitations. As TGF- $\beta 1$ is known as a key mediator in the development of endothelial dysfunction, measurement of flow mediated dilatation could have been helpful but it was not carried out. In addittion, longer duration of therapy may be required for definitive conclusions, since some reports, especially about metformin therapy, have shown that for a benefical effect on endothelial function, metformin therapy should be continued for at least 6 months. ${ }^{33}$

In conclusion, type 2 diabetic patients, even without hypertension, microalbuminuria and any other diabetes related complications, have higher levels of circulating TGF- $\beta 1$. Elevated levels of TGF- $\beta 1$ in the long term may contribute to the endothelial and renal injury. Short-term treatment with metformin or rosiglitazone do not have a significant effect on TGF- $\beta 1$ levels. Circulating TGF- $\beta 1$ levels seem to be correlated with age, total and LDL-C and most clearly with FPG, providing a link between hyperglucemia and TGF- $\beta 1$ expression.

\section{REFERENCES}

1. Pagtalunan ME, Miller PL, Jumping-Eagle S, et al, 1997 Podocyte loss and progressive glomerular injury in type II diabetes. J Clin Invest 99: 342-348.

2. Ihlemann N, Stokholm KH, Eskildsen PC, 2002 Impaired vascular reactivity is present despite normal levels of von Willebrand factor in patients with uncomplicated Type 2 diabetes. Diabet Med 19: 476-481.

3. Le Y, Yu X, Ruan L, et al, 2005 The immunopharmacological properties of transforming growth factor beta. Int Immunopharmacol 5: 1771-1782.

4. Grainger DJ, 2004 Transforming growth factor beta and atherosclerosis: so far, so good for the protective cytokine 
hypothesis. Arterioscler Thromb Vasc Biol 24: 399-404.

5. Sarafidis PA, Ruilope LM, 2006 Insulin resistance, hyperinsulinemia, and renal injury: mechanisms and implications. Am J Nephrol 26: 232-244.

6. Anderson PW, Zhang XY, Tian J, et al, 1996 Insulin and angiotensin II are additive in stimulating TGF-beta 1 and matrix mRNAs in mesangial cells. Kidney Int 50: 745-753.

7. Morrisey K, Evans RA, Wakefield L, Phillips AO, 2001 Translational regulation of renal proximal tubular epithelial cell transforming growth factor-beta1 generation by insulin. Am J Pathol 159: 1905-1915.

8. Chen S, Jim B, Ziyadeh FN, 2003 Diabetic nephropathy and transforming growth factor-beta: transforming our view of glomerulosclerosis and fibrosis build-up. Semin Nephrol 23: 532-543.

9. Wang W, Huang XR, Canlas E, et al, 2006 Essential role of Smad3 in angiotensin II-induced vascular fibrosis. Circ Res 98: 1032-1039.

10. Bobik A, Agrotis A, Kanellakis P, et al, 1999 Distinct patterns of transforming growth factor-beta isoform and receptor expression in human atherosclerotic lesions. Colocalization implicates TGF-beta in fibrofatty lesion development. Circulation 99: 2883-2891.

11. Grant PJ, 2003 Beneficial effects of metformin on haemostasis and vascular function in man. Diabetes Metab 29: 6S44-52.

12. Charles MA, Morange P, Eschwege E, Andre P, Vague P, Juhan-Vague I, 1998 Effect of weight change and metformin on fibrinolysis and the von Willebrand factor in obese nondiabetic subjects: the BIGPRO1 Study. Biguanides and the Prevention of the Risk of Obesity. Diabetes Care 21: 1967-1972.

13. Cefalu WT, Schneider DJ, Carlson HE, et al, 2002 Effect of combination glipizide GITS/metformin on fibrinolytic and metabolic parameters in poorly controlled type 2 diabetic subjects. Diabetes Care 25: 2123-2128.

14. Fanghanel G, Silva U, Sanchez-Reyes L, Sisson D, Sotres D, Torres EM, 1998 Effects of metformin on fibrinogen levels in obese patients with type 2 diabetes. Rev Invest Clin 50: 389-394.

15. Mather KJ, Verma S, Anderson TJ, 2001 Improved endothelial function with metformin in type 2 diabetes mellitus. J Am Coll Cardiol 37: 1344-1350.

16. Caballero AE, Delgado A, Aguilar-Salinas CA, et al, 2004 The differential effects of metformin on markers of endothelial activation and inflammation in subjects with impaired glucose tolerance: a placebo-controlled, randomized clinical trial. J Clin Endocrinol Metab 89: 3943-3948.

17. Haffner SM, Greenberg AS, Weston WM, Chen H, Williams K, Freed MI, 2002 Effect of rosiglitazone treatment on nontraditional markers of cardiovascular disease in patients with type 2 diabetes mellitus. Circulation 106: 679-684.
18. Pistrosch F, Passauer J, Fischer S, Fuecker K, Hanefeld M, Gross P, 2004 In type 2 diabetes, rosiglitazone therapy for insulin resistance ameliorates endothelial dysfunction independent of glucose control. Diabetes Care 27: 484-490.

19. Bakris G, Viberti G, Weston WM, Heise M, Porter LE, Freed MI, 2003 Rosiglitazone reduces urinary albumin excretion in type II diabetes. J Hum Hypertens 17: 7-12.

20. Alessi MC, Bastelica D, Morange P, et al, 2000 Plasminogen activator inhibitor 1, transforming growth factor-beta1, and BMI are closely associated in human adipose tissue during morbid obesity. Diabetes 49: 1374-1380.

21. Blobe GC, Schiemann WP, Lodish HF, 2000 Role of transforming growth factor beta in human disease. N Engl J Med 342: 1350-1358.

22. Ashcroft GS, Yang X, Glick AB, et al, 1999 Mice lacking Smad3 show accelerated wound healing and an impaired local inflammatory response. Nat Cell Biol 1: 260-266.

23. Rossert J, Terraz-Durasnel C, Brideau G, 2000 Growth factors, cytokines, and renal fibrosis during the course of diabetic nephropathy. Diabetes Metab 26: 16-24.

24. Yener S, Demir T, Akinci B, et al, 2007 Transforming growth factor-beta 1 levels in women with prior history of gestational diabetes mellitus. Diabetes Res Clin Pract 76: 193-198.

25. Grant PJ, 2005 Inflammatory, atherothrombotic aspects of type 2 diabetes. Curr Med Res Opin 21: S5-12.

26. McCartney-Francis NL, Frazier-Jessen M, Wahl SM, 1998 TGF-beta: a balancing act. Int Rev Immunol 16: 553-580.

27. Letterio JJ, Roberts AB, 1998 Regulation of immune responses by TGF-beta. Annu Rev Immunol 16: 137-161.

28. Suzumura A, Sawada M, Yamamoto H, Marunouchi T, 1993 Transforming growth factor-beta suppresses activation and proliferation of microglia in vitro. J Immunol 151: 2150-2158.

29. Li Z, Froehlich J, Galis ZS, Lakatta EG, 1999 Increased expression of matrix metalloproteinase- 2 in the thickened intima of aged rats. Hypertension 33: 116-123.

30. Lakatta EG, 2003 Arterial and cardiac aging: major shareholders in cardiovascular disease enterprises: Part III: cellular and molecular clues to heart and arterial aging. Circulation 107: 490-497.

31. Wang M, Lakatta EG, 2002 Altered regulation of matrix metalloproteinase- 2 in aortic remodeling during aging. Hypertension 39: 865-873.

32. Wang M, Zhang J, Spinetti G, et al, 2005 Angiotensin II activates matrix metalloproteinase type II and mimics ageassociated carotid arterial remodeling in young rats. Am J Pathol 167: 1429-1442.

33. Diamanti-Kandarakis E, Paterakis T, Alexandraki K, et al, 2006 Indices of low-grade chronic inflammation in polycystic ovary syndrome and the beneficial effect of metformin. Hum Reprod 21: 1426-1431. 